\title{
A Small-Scale Technique for Evaluation of the Effect of Spray Oils and Other Materials on Sugarcane Yields ${ }^{1}$
}

\author{
N. E. Delfel, E. Cabanillas, and E. Ortiz-Torres?
}

INTRODUC'TION

Dr. H. Guyot, of I.F.A.C., Guadeloupe, F.W.I., has found $(4)^{3}$ that the low-volume application of oil to sugarcane at the beginning of the rainy season tends to prevent the decrease in the yield of sucrose normally found at that time of year. He suggested that the effect of the oil may be to prevent the utilization of stored sugar for new growth. Although the results of some trials in other areas have been at variance with those of Dr. Guyot, the problem of increasing sugar production is sufficiently important to warrant further evaluation of the effect of oil on sugarcane and the extension of the study to include the use of some of the newer growth-regulating compounds. The purpose of the present experiment was to develop a smallscale technique for the rapid evaluation of oils or other materials which might increase sucrose yields when applied as a mist to leaves of the sugarcane plant.

\section{MATERIALS AND METHODS}

Two rows of 1-year-old PR. 980 sugarcane in a commercial field near the Mayagüez Airport were used for this experiment. ${ }^{4}$ Sixteen stools were reserved as prespray controls; the remaining 140 stools were divided into 14 blocks of 10 stools each. Alternate stools in cach block were sprayed with oil at a rate equivalent to 2 gallons per acre.

The spray technique consisted in enclosing the entire stool within a large "tent" during the application of the oil. The tent was made of cloth and wire hoops in the form of a cylinder 3 feet in diameter by 17 feet in height, surmounted by a cone 3 feet high. The tent and the spray operator were supported over the stool being sprayed by means of a large power truck having a bucket on the end of a movable arm. ${ }^{5}$ The oil was discharged into the tent through the apex of the cone with a compressed-air spray gun as

${ }^{1}$ In cooperation with the Agricultural Experiment Station of the University of Puerto Rico, Río Piedras, P.R.

${ }^{2}$ Chemist, Agricultural Aid, and Agronomist, respectively, Federal Experiment. Station, Agricultural Research Service, USDA, Mayagüez, P.R.

${ }^{3}$ Italic numbers in parentheses refer to Literature Cited, p. 333.

- Made available through the courtesy of Mr. Fernando Quiñones-P'ina.

${ }^{5}$ Kindly made available by the P.R. Water Resources Authority. 
in the technique developed to apply oil experimentally to banana leaves (1). The tips of the cane leaves were positioned 7 feet below the spray gun, and the oil spray was allowed to settle for 30 seconds before removing the tent.

In preliminary trials the oil was sprayed on aluminum foil placed 7 feet below the spray gun, the same distance used in the field between the plant and the gun, to check the reproducibility of the method, and to determine the amount of oil to spray in order to obtain a deposit level of 2 gallons per acre, or $0.087 \mathrm{ml}$. per square foot. The volume of oil delivered to the gun was measured with a 5-ml. measuring pipet inserted into the top of the gun through a gas fitting. The weight of oil deposited on the foil was determined by differential weighing and converted to volume by dividing by the density of the oil.

The oil used in this study was a light naphthenic oil ${ }^{6}$, and was similar to that used by Dr. Guyot in his study. The viscosity was 75 SUS at $100^{\circ} \mathrm{F}$., the unsulfonated residue 93 percent, and the density $0.874 \mathrm{gm} . / \mathrm{ml}$.

On the day the oil was applied, May 9, 1961, 16 stools were harvested to establish the initial sucrose level. Every 9 days thereafter for five harvest periods, one oil-sprayed stool and one control stool were selected at random for harvesting from each of the 14 blocks in the experiment. Each stool was divided into two separate samples, one consisting of the three most mature canes in the stool, as selected by visual estimation, the other consisting of the remaining canes in the stool. Each sample was milled separately in a "Cuban-type" single-roller mill. The juice was analyzed according to Horne's dry lead subacetate method (5). For each sample, the total weight of cane, the weight of bagasse, the weight of juice, and the percentage of sucrose in the juice were determined. The extraction efficiency, or weight of sugar recovered in juice/total weight of sugar in cane, of the mill was determined (5) to be 46 percent. Data on the daily rainfall before and during the test period were obtained from the weather station at the nearby Mayagüez Airport.

\section{RESULTS}

The Paasche air gun used produces a very uniform mist and is well suited for small-scale studies of this sort. The reproducibility of the sprayoil deposit at a distance of 7 feet from the spray gun, as determined by the use of aluminum foil, was found to be within plus or minus 5 percent of the average value. This may be compared to results obtained by the aerial application of oil $(3)$ wherein the amount of oil deposited was found to vary plus or minus 54 percent of the average deposit level. In our experience, over 20 plants per hour can be sprayed using this technique.

6 Esso spray oil "C", supplied by Esso Standard Oil, S.A. 
The results of the sucrose determinations were calculated on the basis of percentage of sucrose per weight of cane. The results were calculated on the basis of the three most mature canes in each stool and also on the basis of the whole stool, the latter values being calculated by taking the weighted average of the three-cane and the rest-of-stool results.
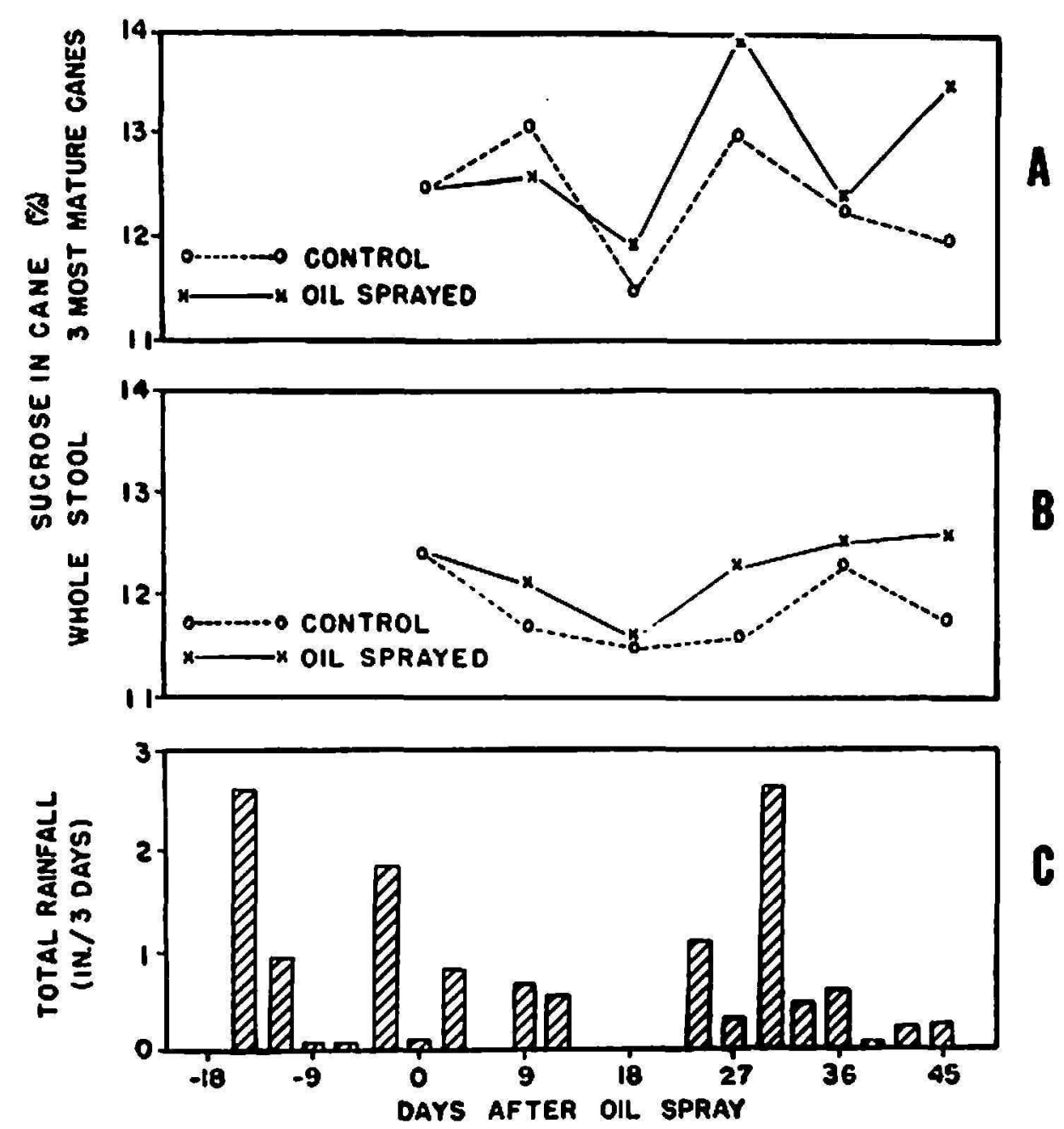

FIG. 1.-The effect of a light agricultural spray oil on the percentage (w/w) of sucrose in PR. 980 sugarcane at various times after application. Data are shown for the 3 most mature canes in each stool (A) and for the whole stool (B). The rainfall during the time of the test is shown in $\mathrm{C}$ as the total inches per 3-day period.

The results of the sucrose determinations on the oil-sprayed and control plants are shown in figure 1, together with the rainfall data. Each sucrose value represents the average of 14 replications. The graph shows that there was no marked decrease in the percentage of sucrose in the cane over the course of the experiment. The sucrose levels in the three most mature canes tended to be higher and fluctuated more than the sucrose levels in the whole stool. With the exception of the 3-cane data 9 days after oil 
application, the oil-sprayed plants were from 0.1 to 1.5 percent higher in sucrose than the control plants.

The above data were analyzed statistically by analysis of variance for a split-plot design. ${ }^{7}$ It was found that the apparent beneficial effect of oil was of borderline significance, i.e. confidence level between 90 and 95 percent, in both the 3-cane and whole-stool data. The difference in sucrose levels from one block to another was found to be significant $(P \geqq 95$ percent) in both the 3-cane and whole-stool data. This is a reflection of the variability in the plants noted in the field at the time of the experiment. The effect of time was significant only in the 3-cane data, indicating that the fluctuation in sucrose levels noted from one sampling period to the next in this group was real.

The weight of cane per stool ranged from 6 to 104 pounds. The oilsprayed stools averaged slightly higher than the unsprayed stools-23.4 vs. 23.1 pounds/stool, respectively, but this difference was not significant.

The rainfall immediately before and during the test is shown in figure 1, C. Each bar represents the total rainfall in inches over a 3-day period. There appeared to be scme tendency for the sucrose levels to decrease about 9 to 14 days after a heavy rain, but the data are not extensive enough to verify this observation.

\section{DISCUSSION}

The use of the present technique permits the application of small amounts of oil precisely and reproducibly in a manner duplicating field conditions. It was expedient in the present study to use a power truck to support the tent and spray operator since the cane was 11 to 14 feet tall, but it would not be difficult, especially when working with shorter cane, to support the tent with a light framework and conduct the spraying operation from the ground.

A comparison of two different sampling methods showed that there was a greater fluctuation in the sucrose levels in the threc most mature canes in the stool than in the whole stool. The level of significance of the effect of oil was the same in both cases, suggesting that the more mature canes are no more sensitive to the action of oil than the stool as a whole. Since whole-stool data are easier to relate to full-scale production, the sampling of the whole stool would be preferable for future experiments.

With the coefficient of variance found in this experiment it would be possible to determine differences in yield of 10 percent at a confidence level

7 The authors wish to express their gratitude to the Biometrical Services, Agricultural Research Service, USDA, Beltsville, Md., for assistance in analyzing these data. 
of 95 percent by using 20 replicates per treatment (2). The finding of a significant block effect suggests that most of the variability was due to differences in growing conditions from one part of the field to the other. It should therefore be possible to increase the precision of this test in two different ways: 1 , By using only very uniform fields of cane for experiments of this type; 2 , by reducing the block size to include only the control and treated samples to be harvested on a given day and excluding samples for harvesting at earlier or later time periods. This would give a closer comparison of the treated $v s$. control plants at the expense of some information on the variation in sucrose levels with time.

It should also be remembered that the experimenter may wish to use a lower confidence level than 95 percent in selecting materials for further trials, for although this increases the chances of including some ineffective materials in such trials, it decreases the chances of overlooking an effective material.

The conditions encountered in this experiment may not have been ideal for demonstrating a beneficial effect of the oil. The weather was unusually dry for the Mayagüez area; not only was the rainfall during the time of the test substantially less than the 50-year average, but there was also an 18-day period of no rainfall 3 weeks before the start of the test. This could have accounted, in part, for the high sucrose levels found in the cane throughout the test period. The effect of oil might have been seen more clearly if the sucrose levels in the control cane had shown a decrease with time. In evaluating the results of the oil application it should also be remembered that the amount and type of oil to use for optimum results has not yet been determined.

Field testing on a small scale makes possible the rapid screening of a large number of compounds without the expense or the risk of damaging large stands of cane. In some cases the amount of material available for testing is limited. The use of the technique developed in this study permits the application of small amounts of oil or other materials precisely and reproducibly in a manner duplicating large-scale field conditions.

\section{SUMMARY}

A technique was developed for the precise low-volume application of liquids to individual stools of cane as a part of a study of the possible effect of agricultural spray oils or other materials in preventing a seasonal decrease in the sugar yields from sugarcane. With this technique differences in yield of 10 percent can be determined using approximately 20 stools per treatment. In a preliminary test of the effect of an agricultural spray oil on sugar yield in PR. 980 cane in western Puerto Rico, a deposit level of 2 
gallons of oil per acre gave a slight increase in yield which was of borderline statistical significance.

\section{RESUMEN}

Se desarrolló una técnica para la aspersión precisa de líquidos a bajo volumen, a cepas individuales de caña, como parte de un estudio del posible efecto de aceites y otros materiales para evitar bajas en el rendimiento de azúcar. Mediante esta técnica, diferencias de 10 por ciento en rendimiento pueden ser determinadas usando aproximadamente 20 cepas por tratamiento. En la parte oeste de Puerto Rico, usando la variedad PR. 980, la asperción de 2 galones de aceite por acre pareció inducir un aumento leve en el rendimiento.

\section{LITERATURE CITED}

1. Calpouzos, L., Brun, W. A., Theis, T., and Colberg, C., A precision spray technique for evaluating oils for Sigatoka disease control on individual banana leaves in the field, Phytopalhology 50 69-72, 1960.

2. Davies, O. L. [Ed.], The Design and Analysis of Industrial Experiments, Hafner Publishing Co., New York, N.Y., 636 pp., 1956.

3. Delfel, N. E., and Samuels, G., unpublished data.

4. Guyot, H., personal communication.

5. Spencer, G. L., and Meade, G. P., Cane Sugar Handbook, John Wiley and Sons, Inc., New York, N.Y., 8th ed., 834 pp., 1948. 